\title{
Rare Variants of Ependymoma: A Report of Four Cases and a Review of the Literature
}

\author{
Murad A. Alturkustani, FRCPC, MBBS \\ Department of Pathology, Faculty of Medicine \\ King Abdulaziz University, Jeddah, Saudi Arabia
}

\section{Correspondence}

Dr. Murad A. Alturkustani

P.O Box 80205, Jeddah 21589

Saudi Arabia

e.M: alturkustani.murad@gmail.com

Submission: 06 Jun. 2016

Accepted: 25 Jun. 2016

\section{Citation}

Alturkustani MA. Rare variants of ependymoma: a report of four cases and a review of the literature. JKAU Med Sci 2016; 23 (3): 39-50. DOl: 10.4197/Med. 23.3.5

\begin{abstract}
Ependymomas are brain tumors that have a wide spectrum of morphological patterns. Rare or unusual patterns of ependymoma can resemble other neoplasms and result in erroneous diagnosis, and management. Four out of 22 ependymoma cases in the pathology archive of King Abdulaziz University Hospital in the last decade had these patterns. The first case was of ependymoma with multinodular growth and different types of ependymal differentiation, including subependymoma, classic ependymoma, and astroblastoma. Dysplastic neurons were associated with the neoplastic growth. This combination can be interpreted as ganglioglioma (i.e., with ependymoma representing the glial component, World Health Organization grade I) or alternatively as ependymoma with dysplastic neurons (World Health Organization grade II). The second case was of a rare variant of intracranial extra-axial ependymoma with lobular and papillary architecture. The third case was of a previously unreported combination of clear cell and giant cell ependymoma. The fourth case was of epithelioid ependymoma with fibrillary background and a peculiar arrangement of the tight clustered epithelioid cells. This report expands the morphological spectrum of ependymoma by introducing different, previously unreported combinations of patterns that were observed in individual tumors, as well as rare locations and architectures.
\end{abstract}

\section{Keywords}

Ependymoma; Dysplastic neurons; Glioma; Morphological patterns; Brain tumor

\section{Introduction}

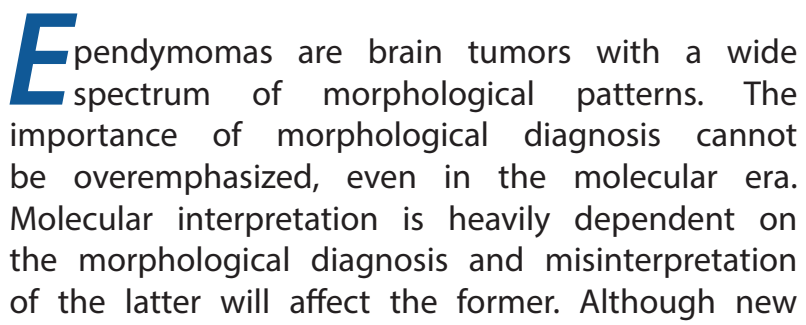

molecular classification of ependymal tumors proved to be a better predictor of prognosis ${ }^{[1]}$, morphological recognition of these rare variants as ependymoma is essential to guide subsequent molecular tests

The World Health Organization [WHO] classification of ependymoma focuses on a few variants (i.e., cellular, papillary, clear cell, and tanycytic ependymoma), while only listing other, rare variants ${ }^{[2]}$. The updated 2016 
WHO classification of CNS tumors, focusing on the integrated pathological and molecular subgrouping for better understanding of the biological behavior of ependymomas, adopted the RELA fusion-associated group as a distinct entity of ependymoma ${ }^{[3]}$. Molecular testing essential for this new classification was not available. However, the main aim of this study is morphological recognition of these rare variants. The current report presents 4 unusual cases that expand the current state of knowledge regarding rare variants of ependymoma, illustrate the combination of different patterns in the same ependymoma tumor, and highlight the unusual locations of rare variants with peculiar architectures.

\section{Materials and Methods}

Prior to the study, approval was obtained from the Research Committee of the Biomedical Ethics Unit of the Faculty of Medicine of King Abdulaziz University (Jeddah, Saudi Arabia). I searched the archive of the pathology department for any cases with a pathological diagnosis of ependymoma during the period 2006-2016. I excluded common cases, and only selected those with unusual or rare morphological or radiological features. Four cases of surgically resected glial tumors with ependymal differentiation were reviewed. The clinical data (sex, age at onset, and surgical intervention), imaging study findings, and pathological findings of these cases were retrospectively reviewed. All included patients were followed up until May 2016.

Tissue sections were cut to a thickness of $4 \mu \mathrm{m}$ and stained using standard procedures. The sections were routinely treated with the hematoxylin and eosin (H\&E) stain. Automated immunohistochemistry (IHC) was carried out on paraffin sections using the Ventana Autostainer (BenchMark XT, Ventana Medical Systems, Inc.; Oro Valley, AZ, USA) and visualized with the ultraView Universal Diaminobenzidine (DAB) Detection Kit (Ventana Medical Systems, Inc., AZ, USA). The following primary antibodies were included: glial fibrillary acidic protein (GFAP; EP672Y; Cell Marque, Rocklin, CA, USA), R132 IDH1 (Dianova, Hamburg, Germany; $\mathrm{H} 09$ clone, monoclonal, predilute), epithelial membrane antigen (EMA; E28, Ventana Medical Systems Inc.; predilute), CD99 (O13; Ventana Medical Systems, Inc.; predilute), synaptophysin (SYN; SP11; Ventana Medical Systems, Inc.; predilute), neurofilament protein (2F11; Cell Marque; predilute), S100 (4C4.9; Ventana Medical Systems, Inc.; predilute), Ki-67 (30-9; Ventana Medical Systems, Inc.; prediluted), p53 (DO-7; Ventana Medical Systems, Inc.; predilute).

\section{Results}

Twenty-two cases of ependymoma were found in our archive and reviewed. The pathological features in four cases had previously unreported combinations of patterns that were observed in individual tumors, rare locations and architectures or rare patterns. The clinical characteristics and radiological findings of the 4 cases are summarized briefly in Table 1 . The following sections of this report will concentrate on the pathological features of the cases.

Table 1. Clinical history and imaging characteristics of the 4 reported cases.

\begin{tabular}{|c|c|c|c|c|c|}
\hline Case & Age/Sex & Symptoms & Imaging & Management & Follow-up \\
\hline 1 & $7 \mathrm{yr} / \mathrm{F}$ & $\begin{array}{l}\text { Seizure and vomiting for } 5 \text { months. Two } \\
\text { previous resections (at ages } 4 \text { and } 5.5 \\
\text { yr) at the same side, performed in a } \\
\text { different country with no available data }\end{array}$ & $\begin{array}{l}\text { MRI: Right frontal, well circumscribed, } \\
\text { solid and cystic with enhancement of } \\
\text { the cyst wall }\end{array}$ & GTR & No recurrence, 3 months \\
\hline 2 & 18 months/M & $\begin{array}{l}\text { Seizure for } 7 \text { months with no relevant } \\
\text { prenatal, intranatal, or postnatal history }\end{array}$ & $\begin{array}{l}\text { CT: Large interhemispheric solid mass } \\
\text { with scattered cystic changes (Fig. 2a) } \\
\text { and postcontrast enhancement }\end{array}$ & GTR & No recurrence, 12 months \\
\hline 3 & $19 \mathrm{yr} / \mathrm{F}$ & $\begin{array}{l}\text { Left-sided weakness, headache, and } \\
\text { vomiting for } 1 \text { day }\end{array}$ & $\begin{array}{l}\text { MRI: Right frontal, well circumscribed, } \\
\text { solid and cystic with variable } \\
\text { enhancement. }\end{array}$ & STR and radiotherapy & $\begin{array}{l}\text { Recurred after } 4 \text { months, } \\
\text { followed by another STR } \\
\text { and no subsequent } \\
\text { recurrence for } 2 \text { months (to } \\
\text { date) }\end{array}$ \\
\hline 4 & $5 \mathrm{yr} / \mathrm{M}$ & Headache and vomiting for 3 months & $\begin{array}{l}\text { MRI: Right frontal, solid, not well } \\
\text { circumscribed with heterogeneous } \\
\text { enhancement }\end{array}$ & GTR & $\begin{array}{l}\text { Multiple intracranial } \\
\text { metastasis, } 2 \text { years }\end{array}$ \\
\hline
\end{tabular}




\section{Case 1}

The investigated specimen was the result of the third resection (in 3 years) of the tumor from the same site, most likely representing residual tumor from a previous, incomplete resection. The previous resections were performed in another country, and little information was available regarding the surgical intervention.

The histological features of this neoplasm showed heterogeneous areas of glial neoplasm with different forms of ependymal differentiation, including subependymoma, classic ependymoma, and astroblastoma, along with scattered dysplastic neurons. The tumor was well demarcated from the adjacent brain and was arranged in solid sheets and infiltrative nodules (Fig. 1a). The nodules could be separated into 2 types depending on the glial cells in the background, but both types were associated with multiple microcysts. The glial cells in the first type of nodule were characterized by eccentric nuclei and glassy cytoplasm resembling gemistocytes (Fig. 1b). In contrast, the glial cells in the second type of nodule and most solid areas formed variable cellular clusters of bland-looking, oval nuclei with dense fibrillary background (Fig. 1c). The focal areas of low cellularity with dense fibrillary and microcystic background appeared very similar to subependymoma. GFAP immunostain highlighted the differences between the glial cells in these 2 nodule types, with dense cytoplasmic staining in the first type and fibrillary staining in the second type (Fig. 1d). There were focal areas of classic ependymoma with perivascular pseudorosette formation (Fig. 1e). Further, there were other areas with neoplastic glial cells that formed non-tapering cytoplasmic processes radiating around blood vessels, which is characteristic of astroblastoma (Fig. 1f). CD99 immunostain showed background staining in areas with the fibrillary background, as well as characteristic dot-like cytoplasmic staining in the neoplastic cells, confirming the ependymal differentiation in the neoplastic cells (Fig. 1g). In contrast, EMA immunostaining was negative.

The other interesting components in this neoplasm were the scattered, haphazard arrangement of dysplastic neurons with large eosinophilic cytoplasm and the peripheral distribution of Nissl substances (Fig. $1 \mathrm{~h})$. The dysplastic neurons were more numerous in the solid areas, while only a few were located inside the nodules. These neurons showed cytoplasmic reactivity for phosphorylated neurofilament and synaptophysin immunostain (Fig. 1i). Other features of ganglioglioma-like eosinophilic granular bodies and significant perivascular lymphocytes were not identified. There was no significant mitosis, no necrosis, and no endothelial proliferation. The Ki-67 proliferative index was approximately 3-5\%. IDH1, CD34, and P53 immunostaining were negative. Molecular testing for BRAF V600E mutation was not available.

In this case, the differential diagnoses were glioma with a different type of ependymal differentiation and dysplastic neurons (WHO grade II) and ganglioglioma with the glial part represented by a different type of ependymal differentiation (WHO grade I). This differential is described in greater detail in the Discussion section.

\section{Case 2}

The interesting aspect of this tumor was the extra-axial location, which was observed on computed tomography scanning (Fig. 2a) and raised differential diagnoses of meningioma and metastasis. Histopathological examination of the tumor showed clear demarcation of the tumor from the cortical ribbon, which confirmed the extra-axial location of the tumor (Fig. 2b). The tumor was arranged in solid sheets, lobules, and papillary projections (Fig. 2c, 2d). Perivascular arrangement was prominent, with glial processes radiating toward the central blood vessels (Fig. 2e). There was no hyalinization of the blood vessels. The neoplastic cells were round to oval with fine granular chromatin. There was a small focus of necrosis with no peripheral palisading, no endothelial proliferation, and only a few mitoses. The Ki-67 proliferative index range from 5 to $10 \%$. Immunostaining with GFAP showed diffuse strong immunopositivity in the tumor cells, while EMA showed only focal dot-like staining in the cytoplasm (Fig. 2f). The histological diagnosis was ependymoma with papillary and lobular configuration (WHO grade II/III).

\section{Case 3}

Histological examination showed sheets of monotonous round neoplastic cells with numerous giant cells arranged in solid sheets that were separated into small nests by branching blood vessels. There were small rims of nuclear-free zones around these blood vessels, but none of the conspicuous perivascular pseudorosette formation that is typical of classical ependymoma (Fig. 3a). The neoplastic cells had infiltrated the adjacent cortex in small tight clusters. The small round 


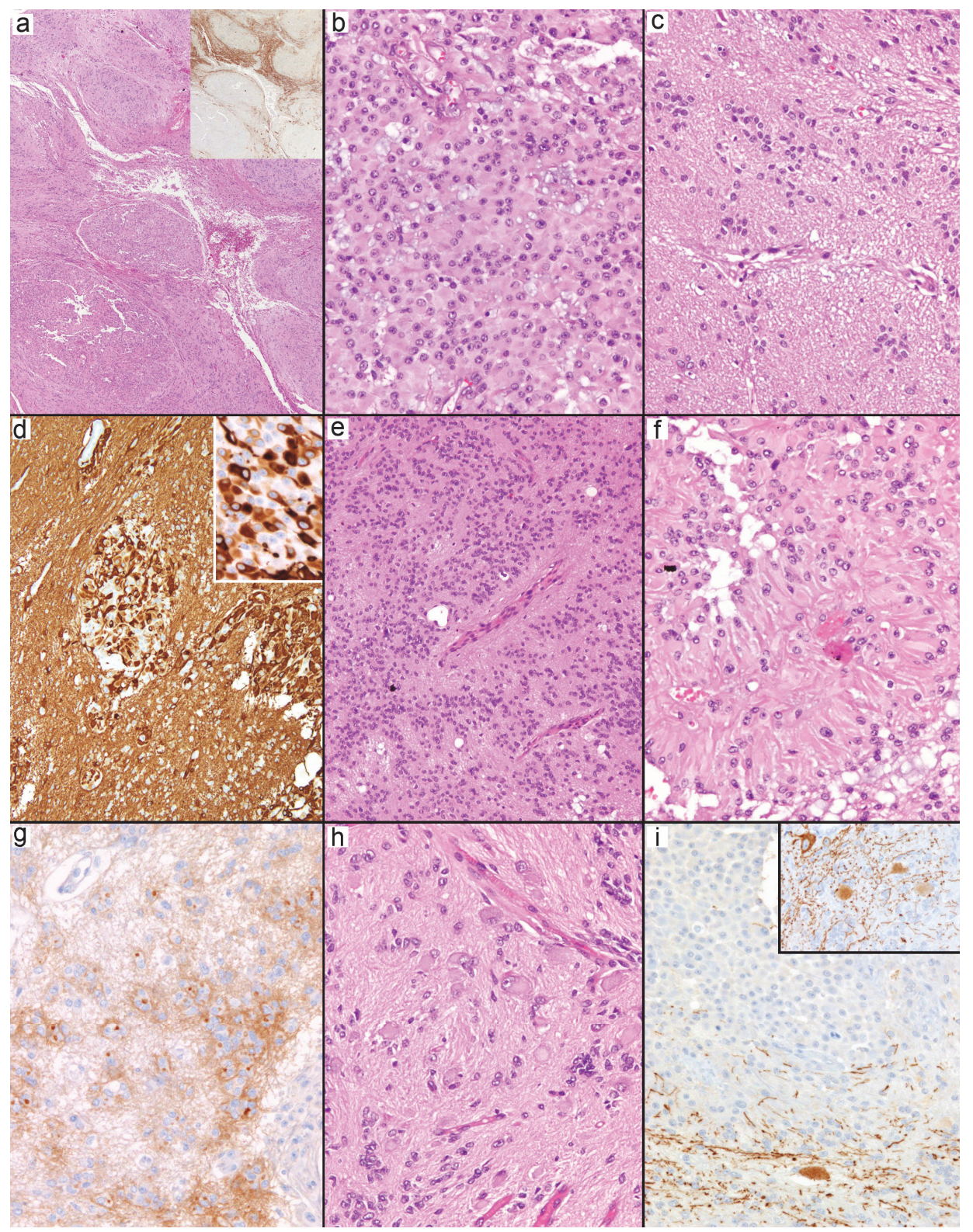

Figure 1. Ependymoma with dysplastic neurons/ganglion cells. (a) Multiple, well-demarcated nodules of the neoplasm infiltrate through the brain (hematoxylin and eosin [H\&E]; original magnification: 40x). The brain parenchyma is highlighted by synaptophysin immunostain, which is similar to the staining pattern of phosphorylated neurofilament immunostain (inset: synaptophysin; original magnification: 40x). There are 2 types of nodules, both of which are formed by glial cells and microcysts: (b) The first type contains glial cells with eccentric nuclei and glassy cytoplasm resembling gemistocytes (H\&E; original magnification: 400x); (c) The second type of nodules show fibrillary background and clusters of bland-looking oval nuclei in a distribution that is similar to the architecture of the subependymoma (H\&E; original magnification: 400x); (d) Solid sheets of fibrillary areas are interrupted by well-demarcated small nodules of the first type (glial fibrillary acidic protein [GFAP] immunostain; original magnification: 200x) (inset: GFAP; original magnification: 400x) (e) Focal areas show classic ependymoma with perivascular pseudorosettes formation (H\&E; original magnification: 200x); (f) Focal areas show astroblastic differentiation with neoplastic cells that form thick non-tapering processes around blood vessels (H\&E; original magnification: 200x); (g) CD99 shows background staining in areas with the fibrillary background, as well as characteristic dot-like cytoplasmic staining in the neoplastic cells (CD99; original magnification: 400x); (h) Dysplastic neurons are numerous. Most of the dysplastic neurons are outside of the nodules and are associated with the areas with fibrillary background (H\&E; original magnification: 400x); (i) Dysplastic neurons show cytoplasmic reactivity for phosphorylated neurofilament as well as greater reactivity with synaptophysin immunostain (SMI31; original magnification: 400x) (inset: SMI31; original magnification: 400x). 
Rare Variants of Ependymoma: A Report of Four Cases and a Review of the Literature M.A. Alturkustani

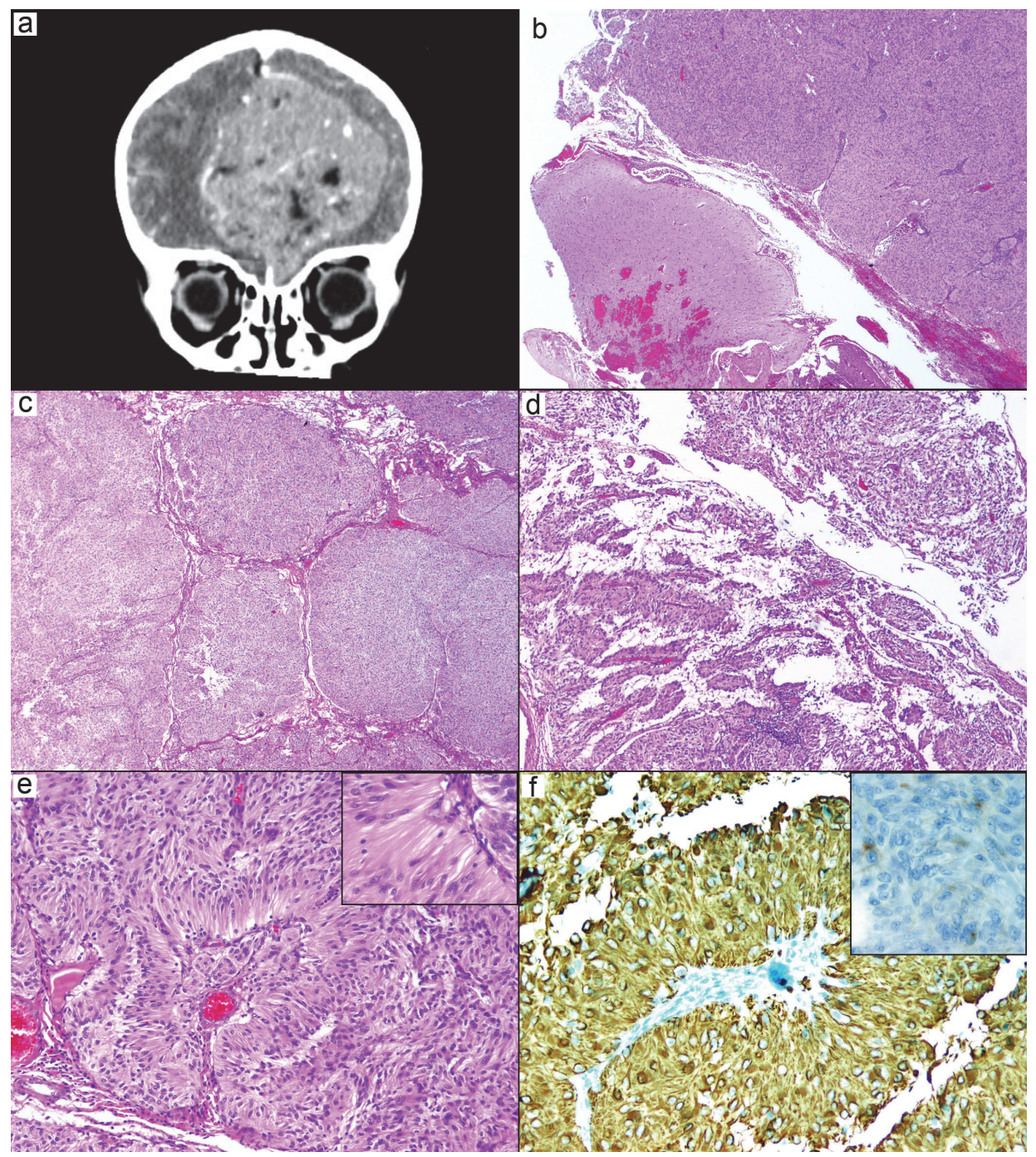

Figure 2. (a) A post-contrast computed tomography (CT) scan shows a large, interhemispheric, extra-axial, lobulated, solid-enhancing mass with few cysts; (b) There is clear demarcation of the tumor from the cortex (hematoxylin and eosin [H\&E]; original magnification: 20x); (c) Multilobular architecture of the ependymoma (H\&E; original magnification: 40x); (d) Papillary configuration of the ependymoma (H\&E; original magnification: 40x); (e) Perivascular arrangement of the tumor cells with glial processes radiating toward the blood vessels (H\&E; original magnification 100x) (inset: H\&E; original magnification: 400x); (f) Tumor cells show strong glial fibrillary acidic protein immunostaining (GFAP; original magnification 200x) and dot-like immunoreactivity for epithelial membrane antigen (inset: EMA; original magnification: 400x). 


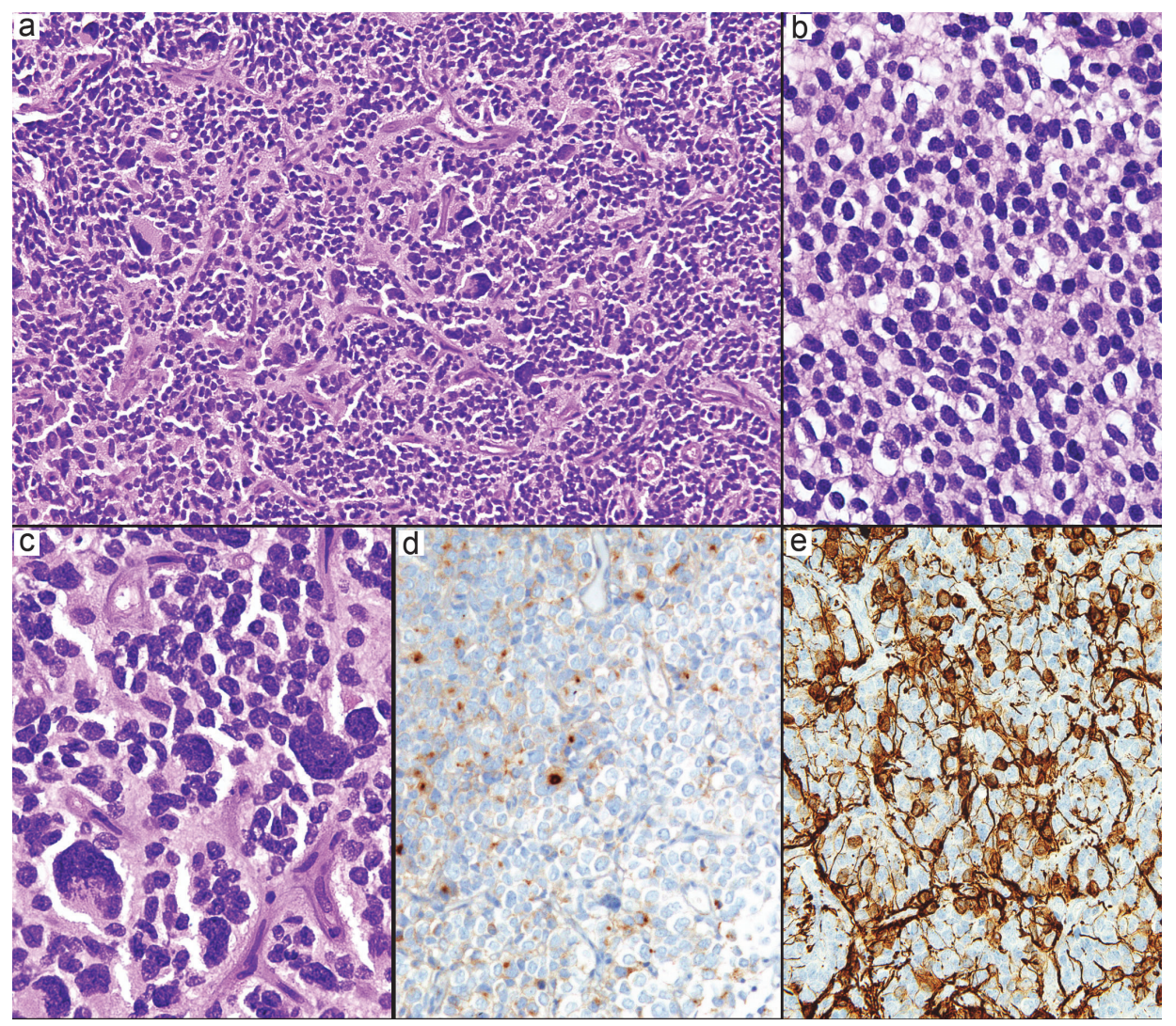

Figure 3. Clear cell ependymoma with giant cells. (a) The neoplastic cells are arranged in small nests separated by branching blood vessels with numerous giant cells (hematoxylin and eosin [H\&E]; original magnification: 100x); (b) The even distribution of round neoplastic cells with perinuclear clearing gives the tumor an overall impression of oligodendroglioma (H\&E; original magnification: 400x); (c) Higher magnification view of the giant cells among the neoplastic cells (H\&E; original magnification: 400x); (d) Epithelial membrane antigen (EMA) immunostain show the characteristic dot-like cytoplasmic staining in many neoplastic cells including the giant cells (EMA; original magnification: 400x); (e) Some neoplastic cells are immunopositive for glial fibrillary acidic protein (GFAP) and show perinuclear and/or short process staining, but the rest of the neoplastic cells show no staining for GFAP (GFAP; original magnification: 400x).

neoplastic cells showed perinuclear clearing and were evenly distributed, creating an overall impression of oligodendroglioma (Fig. 3b). Giant cells were numerous and present in most of the tumor. Their chromatin was similar to the smaller cells, but they had irregular nuclear membranes and inconspicuous nucleoli (Fig. 3c). EMA immunostain highlighted the characteristic, dot-like cytoplasmic staining of ependymoma in many of the neoplastic cells, including the giant cells (Fig. 3d). GFAP was immunopositive in approximately $50 \%$ of the neoplastic cells, including the giant cells, and showed perinuclear and/or short process staining (Fig. 3e). Endothelial proliferation was present, but necrosis was absent. The mitotic index was 15/10 high-power fields. The Ki-67 proliferative index was approximately 35\% focally, and Ki-67 staining was observed in some of the giant cells. IDH1 and synaptophysin immunostaining were negative.
The tumor recurred at the same location 3 months after the subtotal resection. The diagnosis was anaplastic clear cell ependymoma with giant cells (WHO grade III). The morphological features of the newly resected specimen were similar to those of the previous sample.

\section{Case 4}

This neoplasm showed characteristic morphological features of ependymoma when under low-power examination, including being well demarcated from the adjacent white matter and perivascular nuclearfree areas (Fig. 4a), as well as showing focal clear cell changes (Fig. 4b). Significant mitoses and focal endothelial proliferation were present, but necrosis was absent, which is consistent with WHO grade III anaplastic ependymoma. 


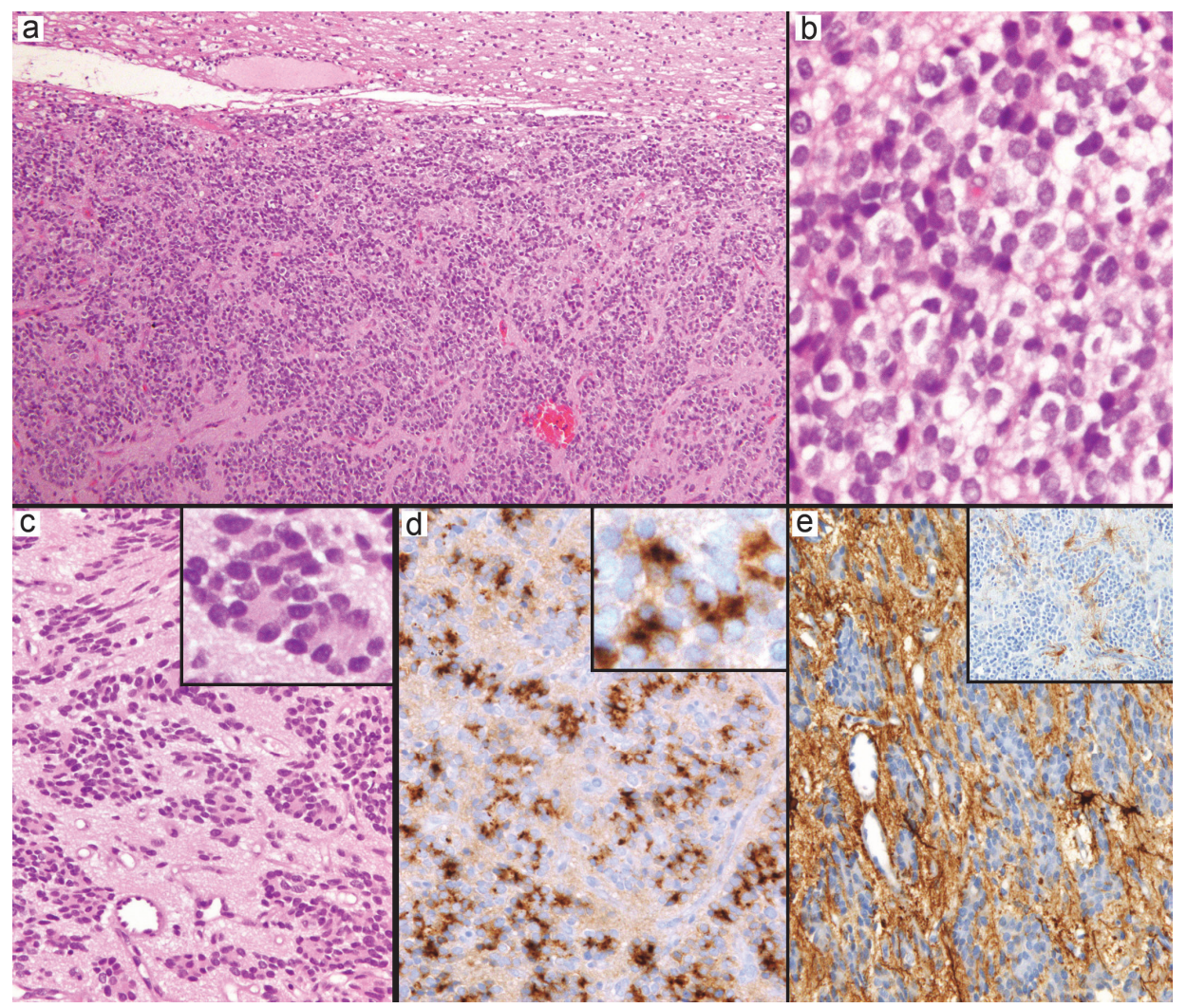

Figure 4. (a) The tumor is sharply demarcated from the adjacent white matter. In addition, perivascular pseudorosettes are evident from this magnification. These two features are almost diagnostic of ependymoma (hematoxylin and eosin [H\&E]; original magnification: 100x); (b) Focal cellular areas are evident with round neoplastic cells that have clear cytoplasm (H\&E; original magnification: 400x); (c) The neoplastic cells are arranged into small, tight clusters of epithelioid cells that have central fused cytoplasmic processes but do not have central lumens resembling "giant cells," which is considered characteristic of epithelioid ependymoma (H\&E; original magnification: 400x) (inset: H\&E; original magnification: 400x); (d) Epithelial membrane antigen (EMA) immunostaining of these giant/epithelioid cells shows intense staining in the inner portion of the cytoplasm (EMA; original magnification: 400x) (inset: EMA; original magnification: 400x); (e) Glial fibrillary acidic protein (GFAP) immunostaining highlights the background and a few reactive astrocytes between the neoplastic cells, but most of the neoplastic cells are immunonegative (GFAP; original magnification: 400x). S100 highlights only the reactive astrocytes, whereas the neoplastic cells and the background are immunonegative (inset: S100; original magnification: 200x).

The interesting feature of this neoplasm was the arrangement of the tumor cells into small tight clusters. These clusters were formed by epithelioid ependymal cells with central fused cytoplasmic processes, but no central lumen. The arrangements of these epithelioid cells resembled giant cells (Fig. 4c), which is considered the hallmark of this entity ${ }^{[4]}$. These clusters also left a nuclear-free zone with fibrillary background, which resembled perivascular pseudorosettes but was not formed by the cytoplasmic processes of the epithelioid neoplastic cells. EMA immunostaining of these giant/ epithelioid cells showed intense staining in the inner portion of the cytoplasm (Fig. 4d). GFAP highlighted the background with few reactive astrocytes, but not the typical perivascular processes in "classic ependymoma" (Fig. 4e).

\section{Discussion}

Ependymoma has many different morphological variants with widely different cell morphologies, such as tanycytic (elongated cells that resemble astrocytes), clear (resembling oligodendrocytes), epithelioid, lipomatous, pigmented, large pleomorphic, and other variants. The many possible morphological variants may lead observers to confuse cases of ependymoma with diffuse glioma. However, most of these variants characteristically feature tumors that are well circumscribed from the adjacent brain tissue, which excludes diffuse glioma and limits the differential diagnoses to a few glial tumors that have wellcircumscribed borders (e.g., pilocytic astrocytoma and ganglioglioma). Other important diagnostic features 
of ependymoma are perivascular pseudorosettes formation, true ependymal rosettes, and the formation of ependymal canal-like structures. Perivascular pseudorosettes are the most common feature that is found in ependymoma, and are formed by the tapering of the cytoplasmic process toward blood vessels.

Most ependymoma are immunopositive for GFAP, which highlights the perivascular accentuation in pseudorosettes. However, clear cell variants are usually only focally positive for GFAP ${ }^{[5]}$, and epithelioid variants have shown variable staining in the few cases that have been reported ${ }^{[4]}$. Although EMA and CD99 immunostaining are commonly applied in cases of ependymoma, their results should be interpreted with caution. CD99 is highly sensitive, but is not specific ${ }^{[6]}$, while EMA has variable sensitivity and specificity, depending on the type of staining in the neoplastic cells. The sensitivity of EMA is much lower than that of $C D 99^{[6,7]}$ and can be negative (as was observed in Case 1 of this study) or only focally positive (as was observed in Case 3 of this study). Cytoplasmic dot- and ring-like EMA stainings correspond to microrosettes ultrastructurally. Dot-like staining can be seen in glioblastoma ${ }^{[2]}$, while ring-like staining is considered specific to ependymoma ${ }^{[7]}$.

The first case in this report was very complicated and addresses 3 topics that are important to ependymoma: the presence of mixed types of ependymal differentiation in the same tumor, the presence of neuritic differentiation in ependymoma, and the relationship of the ependymoma with the adjacent brain tissue. The different types of ependymal differentiation in Case 1 included subependymoma, classic ependymoma, and astroblastoma. The mixture of subependymoma and ependymoma has been reported previously and the WHO grade was assigned to the higher component ${ }^{[8]}$. However, to the best of my knowledge, astroblastoma has not been reported previously with this mixture. Lehman included all of these tumors under the umbrella of tumors of primarily ependymal differentiation ${ }^{[9]}$. The combination of types in this case supports a common origin from precursor cells (i.e., radial glia) with different morphologies that represent the different stages of ependymal cell development ${ }^{[9]}$.

Neuronal differentiation in ependymoma has been documented in 3 forms. The most common form is based on IHC staining (and not on morphological features), especially including neurofilament light polypeptide and, less commonly, other forms of IHC such as NeuN ${ }^{[10]}$.
This type of neuronal differentiation has been associated with a supratentorial location and better prognosis (i.e., longer progression-free survival ${ }^{[10-12]}$. The second type of neuronal differentiation is based on the presence of morphological neuronal differentiation in the form of neuropil-like islands ${ }^{[12,13]}$. Together, these 2 types have been regarded as ependymoma with neuronal differentiation. The third type, is based on the presence of dysplastic neurons ${ }^{[14,15]}$, as were found in Case 1 of this report. This form of ependymal differentiation has been regarded as ganglioglioma with the ependymal differentiation represented in the glial component of the tumor ${ }^{[14,15]}$, rather than ependymoma with neuronal differentiation. Another possible interpretation for this mixture is ependymoma with dysplastic neurons. The latter possibility is favored in the first case because the predominant component was represented by glioma with ependymal differentiation, and because the dysplastic neurons were only scattered in the tumor. The lack of eosinophilic granular bodies despite extensive sampling in the current case-and in contrast with previously reported cases ${ }^{[14]}$-is also contrary to ganglioglioma. BRAF V600E mutation, which can be positive in ganglioglioma, was not analyzed in the first case. Although this issue is difficult to solve, it should not affect the diagnosis in the current case. As in general, the grade and the behavior of ganglioglioma is based on the glioma component (in this case of ependymoma, WHO grade II), and it is therefore better to consider the case as being ependymoma with dysplastic neurons. The behavior of this tumor (2 recurrences in 3 years) is also more compatible with ependymoma than with WHO grade I ganglioglioma.

The third important feature of Case 1 was the presence of multinodular growth with wellcircumscribed infiltrative nodules. Although ependymomas are usually well circumscribed brain tumors, different types of infiltration have been described and are compatible with the diagnosis of ependymoma ${ }^{[16]}$. Similar multinodular growth has been described in a new entity of neuronal tumor, but is not associated with the features of ependymoma ${ }^{[17]}$. To the best of my knowledge, no similar case in the previous literature has included these features. In conclusion, Case 1 is best regarded as ependymoma with dysplastic neurons (WHO grade II).

The second case addresses important concepts regarding the location of ependymoma.

Ependymoma usually occurs near the ventricular system and in the spinal cord; however it has 
been described in all locations in the neuro-axis ${ }^{[2]}$. Supratentorial ependymoma has been described outside the ventricular system and, in rare cases, can be entirely centered within the cerebral cortex (i.e., cortical ependymoma) ${ }^{[18]}$. Pathological assessment of cortical ependymoma has revealed a close resemblance to another low-grade glioma (i.e., angiocentric glioma). Although these diseases show distinct histopathological features, they share a relatively more favorable outcome and behave like WHO grade I tumors ${ }^{[9,18]}$. Intracranial extra-axial ependymoma (IEAE) is a rare tumor with only 16 previously reported cases in the literature ${ }^{[19,20]}$, and only 2 cases reported in children ${ }^{[19]}$.

The second case represents the youngest affected patient. The age of onset of previous cases has ranged from 10 to 81 years, with a mean of 38.4 years ( 12 cases in men and 4 in women) ${ }^{[19,20]}$. The clinical presentations mainly depended on the location of the tumor (8 supratentorial and 8 infratentorial); however, headache and vomiting were the most common presenting features. Other features have included hemiparesis, facial pain, seizure, and visual field defect ${ }^{[19,20]}$. As IEAE is a rare neoplasm, it was not included in the radiological differential diagnosis of our case or the previously reported cases. In most cases, the radiological differential diagnosis depends on the tumor location. For supratentorial tumors, the radiological differential diagnosis has mainly been meningioma, and has included schwannoma in cases of cerebellopontine angle tumors.

Histological examination of Case 2 was diagnostic of ependymoma, but included unusual histological features. A predominant lobular architecture and papillary projections were present, consistent with the papillary variant of ependymoma. Because previous studies have focused on the unusual location of the tumor, the tumor histopathology has only been described briefly in some cases. Other reports with more detailed pathological descriptions have noted the presence of papillary architecture in 4 cases of ependymoma ${ }^{[21-24]}$ and the presence of lobular architecture in no cases of ependymoma. Most cases were of WHO grade II, and only 1 case was diagnosed as WHO grade III ependymoma ${ }^{[20]}$. Because papillary ependymoma is a rare variant of ependymoma ${ }^{[25]}$, the relatively high frequency of this variant in IEAE $(5 / 17$ cases) indicates a morphological correlation with the location in ependymoma.
The prognosis of ependymoma is especially dependent on the location of the tumor, extent of resection, and age of the patient ${ }^{[2]}$. The locations of these tumors make them more accessible to total resection and hence provide a better prognosis. This is similar to cortical ependymoma, which has been suggested to behave more like a WHO grade I tumor ${ }^{[18]}$. Follow-up data were available in 8/16 reported cases, with no recurrence in 7 cases (range of follow up, 6 months to 2.5 years). In the remaining case that was followed up, recurrence developed after 4 months, even though the tumor was completely resected and the pathology showed WHO grade II ependymoma ${ }^{[19]}$. In resemblance with cortical ependymoma, IEAE arises in areas where normal ependymal cells are absent. This supports the theory that the origin of these tumors is progenitor glial cells that differentiate toward ependymal cells. However, other proposed hypotheses cannot be excluded, such as the development of these tumors from heterotopic ependymal cell rests during fetal development ${ }^{[19]}$.

Case 3 included a combination of 2 rare variants of ependymoma that, to the best of my knowledge, has not been reported previously: clear cell and giant cell ependymoma. Giant cell ependymoma is rare variant of ependymoma, with only 21 cases reported in the literature ${ }^{[26]}$. It may occur anywhere in the central nervous system, but has a predilection to the spinal cord, and can be of both WHO grade II and III ${ }^{[26]}$. Giant cell ependymoma is characterized by marked pleomorphic and bizarre nuclei, representing degenerative atypia. Clear cell ependymoma with clear perinuclear halo, round nuclei, and focal positivity for GFAP mimics oligodendroglioma and is easily misdiagnosed as such if clear cell ependymoma is not included in the differential diagnosis. Because the differential diagnosis for clear cell ependymoma is oligodendroglioma, the presence of pleomorphic giant cells can be misinterpreted as polymorphous oligodendroglioma of Zülch ${ }^{[27]}$. However, the fact that the tumor was well demarcated from the adjacent brain and the presence of EMA immunopositivity were diagnostic for ependymoma, rather than oligodendroglioma.

The last case was a rare variant of ependymoma: epithelioid ependymoma. The tumor was characterized by the presence of tight clusters of epithelioid cells that coalesced to form multinucleated giant cells with no central lumen ${ }^{[4]}$. The few previously reported cases 
have been associated with diffuse myxoid background, have lacked perivascular pseudorosette formation, and have shown variable GFAP staining ${ }^{[4]}$. The current case had diffuse fibrillary background with no mucinous changes, and was diffusely immunopositive for GFAP. Although the processes of the neoplastic cells did not form typical perivascular pseudorosettes, the arrangement of the clustered epithelioid cells left nuclear-free zones around the blood vessels, thereby giving the impression of perivascular pseudorosette formation.

In conclusion, the 4 cases that have been described in this report expand the current state of knowledge regarding rare variants of ependymoma and the combinations of different patterns that can be found in the same tumor. Further, the reported cases highlight the unusual locations that are possible for this neoplasm.

\section{Conflict of Interest}

The author has no conflict of interest.

\section{Disclosure}

The author did not receive any type of commercial support either in forms of compensation or financial for this study. The author has no financial interest in any of the products or devices, or drugs mentioned in this article.

\section{Ethical Approval}

Obtained.

\section{References}

[1] Pajtler KW, Witt H, Sill M, Jones DT, Hovestadt V, Kratochwil F, Wani K, Tatevossian R, Punchihewa C, Johann P, Reimand J, Warnatz HJ, Ryzhova M, Mack S, Ramaswamy V, Capper D, Schweizer L, Sieber L, Wittmann A, Huang Z, van Sluis P, Volckmann R, Koster J, Versteeg R, Fults D, Toledano H, Avigad S, Hoffman LM, Donson AM, Foreman N, Hewer E, Zitterbart K, Gilbert M, Armstrong TS, Gupta N, Allen JC, Karajannis MA, Zagzag D, Hasselblatt M, Kulozik AE, Witt O, Collins VP, von Hoff K, Rutkowski S, Pietsch T, Bader G, Yaspo ML, von Deimling A, Lichter P, Taylor MD, Gilbertson R, Ellison DW, Aldape K, Korshunov A, Kool M, Pfister SM. Molecular Classification of Ependymal Tumors across All CNS Compartments, Histopathological Grades, and Age Groups. Cancer Cell 2015; 27(5): 728-743.

[2] McLendon RE, Wiestler OD, Kros JM, Korshunov A, Ng $\mathrm{H}-\mathrm{K}$. Ependymoma. WHO Classification of Tumors of the
Central Tumors of the Nervous System. In: World Health Organization Classification of Tumours. 4th ed. Lyon, France: IARC Press, 2007. 74-78

[3] Louis DN, Perry A, Reifenberger G, von Deimling A, Figarella-Branger D, Cavenee WK, Ohgaki H, Wiestler OD, Kleihues P, Ellison DW. The 2016 World Health Organization Classification of Tumors of the Central Nervous System: a summary. Acta Neuropathol 2016; 131(6): 803-820.

[4] Kleinman GM, Zagzag D, Miller DC. Epithelioid ependymoma: a new variant of ependymoma: report of three cases. Neurosurgery 2003; 53(3): 743-747; discussion 747-748.

[5] Jain D, Sharma MC, Arora R, Sarkar C, Suri V. Clear cell ependymoma: a mimicker of oligodendroglioma--report of three cases. Neuropathology 2008; 28(4): 366-371.

[6] Mahfouz S, Aziz AA, Gabal SM, el-Sheikh S. Immunohistochemical study of CD99 and EMA expression in ependymomas. Medscape J Med 2008; 10(2): 41.

[7] Hasselblatt M, Paulus W. Sensitivity and specificity of epithelial membrane antigen staining patterns in ependymomas. Acta Neuropathol 2003; 106(4): 385-388.

[8] Bi Z, Ren X, Zhang J, Jia W. Clinical, radiological, and pathological features in 43 cases of intracranial subependymoma. J Neurosurg 2015; 122(1): 49-60.

[9] Lehman NL. Central nervous system tumors with ependymal features: a broadened spectrum of primarily ependymal differentiation? J Neuropathol Exp Neurol 2008; 67(3): 177-188.

[10] Hagel C, Treszl A, Fehlert J, Harder J, von Haxthausen F, Kern $\mathrm{M}$, von Bueren $\mathrm{AO}$, Kordes U. Supra- and infratentorial pediatric ependymomas differ significantly in NeuN, p75 and GFAP expression. J Neurooncol 2013; 112(2): 191-197.

[11] Andreiuolo F, Puget S, Peyre M, Dantas-Barbosa C, Boddaert N, Philippe C, Mauguen A, Grill J, Varlet P. Neuronal differentiation distinguishes supratentorial and infratentorial childhood ependymomas. Neuro Oncol 2010; 12(11): 1126-1134.

[12] Rodriguez FJ, Scheithauer BW, Robbins PD, Burger PC, Hessler RB, Perry A, Abell-Aleff PC, Mierau GW. Ependymomas with neuronal differentiation: a morphologic and immunohistochemical spectrum. Acta Neuropathol 2007; 113(3): 313-324.

[13] Gessi M, Marani C, Geddes J, Arcella A, Cenacchi G, Giangaspero F. Ependymoma with neuropil-like islands: a case report with diagnostic and histogenetic implications. Acta Neuropathol 2005; 109(2): 231-234.

[14] Varlet P, Peyre M, Boddaert N, Miquel C, Sainte-Rose C, Puget S. Childhood gangliogliomas with ependymal differentiation. Neuropathol Appl Neurobiol 2009; 35(4): 437-441.

[15] Hayashi S, Kameyama S, Fukuda M, Takahashi H. Ganglioglioma with a tanycytic ependymoma as the glial component. Acta Neuropathol 2000; 99(3): 310-316. 
[16] Lehman NL. Patterns of brain infiltration and secondary structure formation in supratentorial ependymal tumors. J Neuropathol Exp Neurol 2008; 67(9): 900-910.

[17] Huse JT, Edgar M, Halliday J, Mikolaenko I, Lavi E, Rosenblum MK. Multinodular and vacuolating neuronal tumors of the cerebrum: 10 cases of a distinctive seizure-associated lesion. Brain Pathol 2013; 23(5): 515-524.

[18] Van Gompel JJ, Koeller KK, Meyer FB, Marsh WR, Burger PC, Roncaroli F, Worrell GA, Giannini C. Cortical ependymoma: an unusual epileptogenic lesion. J Neurosurg 2011; 114(4): 1187-1194.

[19] Yang X, Ren Y, Wu W, Wang X, Liu X, Zhang Y. Intracranial extra-axial ependymoma involving the petroclival region: a rare case report. Int J Clin Exp Pathol 2014; 7(12): 90679071.

[20] Singh V, Turel MK, Chacko G, Joseph V, Rajshekhar V. Supratentorial extra-axial anaplastic ependymoma mimicking a meningioma. Neurol India 2012; 60(1): 111113.

[21] Donich D, Lee JH, Prayson R. Giant extra-axial cerebellopontine angle/cavernous sinus ependymoma: case report. Neurosurgery 1999; 44(1): 195-198.

[22] Fukui MB, Hogg JP, Martinez AJ. Extraaxial ependymoma of the posterior fossa. AJNR Am J Neuroradiol 1997; 18(6): 1179-1181.

[23] Cosgrove GR, Villemure JG, Robitaille Y, Melanson D. Extraaxial ependymoma of the posterior fossa. Surg Neurol 1985; 24(4): 433-436.

[24] Hanchey RE, Stears JC, Lehman RA, Norenberg MD. Interhemispheric ependymoma mimicking falx meningioma. Case report. J Neurosurg 1976; 45(1): 108112

[25] Grajkowska W, Matyja E, Pronicki M, Daszkiewicz P, Roszkowski M, Perek D, Drogosiewicz M. Papillary ependymoma with unique superficial cortical location: immunohistochemical and ultrastructural studies. A case report. Folia Neuropathol 2009; 47(4): 354-361.

[26] Li JY, Lopez Jl, Powell SZ, Coons SW, Fuller GN. Giant cell ependymoma-report of three cases and review of the literature. Int J Clin Exp Pathol 2012; 5(5): 458-462.

[27] Hewer E, Beck J, Murek M, Kappeler A, Vassella E, Vajtai I. Polymorphous oligodendroglioma of Zulch revisited: a genetically heterogeneous group of anaplastic gliomas including tumors of bona fide oligodendroglial differentiation. Neuropathology 2014; 34(4): 323-332. 


\section{أنماط مجهرية نادرة لورم البطانية العصبية}

$$
\begin{aligned}
& \text { مراد عبدالكريم التركستاني }
\end{aligned}
$$

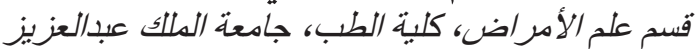

$$
\begin{aligned}
& \text { جدة ـ المدلكة العربية السعودية }
\end{aligned}
$$

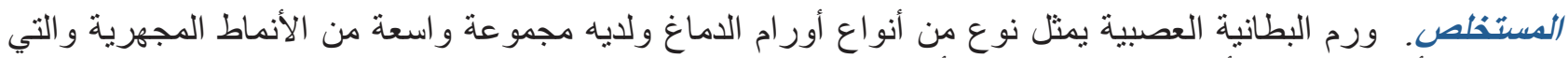

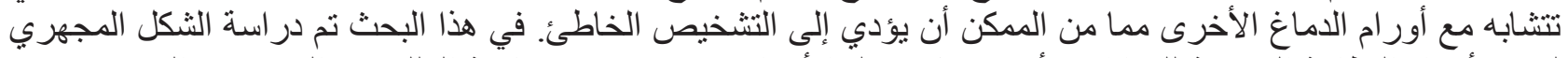

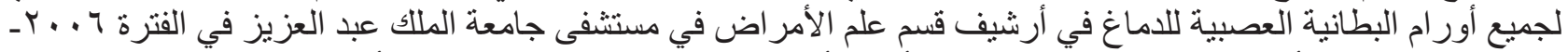

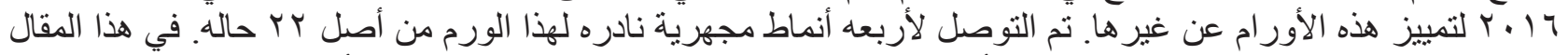

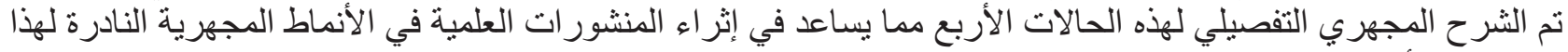

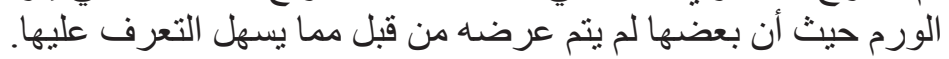

